\title{
Morphological and Taxonomic Reevaluation of Pasteuria ramosa Metchnikoff 1888 and 'Bacillus penetrans' Mankau 1975
}

\author{
R. M. SAYRE, ${ }^{1}$ R. L. GHERNA, ${ }^{2 *}$ AND W. P. WERGIN ${ }^{1}$
}

Plant Protection Institute, Agriculture Research Service, United States Department of Agriculture, Beltsville, Maryland $20705^{1}$ and Bacteriology Department, American Type Culture Collection, Rockville, Maryland $20852^{2}$

\begin{abstract}
The characteristics of a cladoceran parasite and a nematode parasite were compared with the characteristics given in descriptions of Pasteuria ramosa Metchnikoff 1888 and with the characteristics of strain ATCC 27377, the type strain of $\boldsymbol{P}$. ramosa designated by Staley (Can. J. Microbiol. 19:609-614, 1973). The cladoceran and nematode parasites formed endospores and exhibited most of the morphological phases described by Metchnikoff. Strain ATCC 27377 of Staley did not form spores or exhibit the morphological stages described for P. ramosa. Our findings indicate that strain ATCC 27377 is not a member of $P$. ramosa Metchnikoff 1888 and should not be considered the type strain for the genus and species. Because the cladoceran and nematode parasites do conform to the description of $P$. ramosa of Metchnikoff, they appear to be members of the genus Pasteuria.
\end{abstract}

Metchnikoff (8) described the life stages of Pasteuria ramosa, a parasite found in the hemolymph of the water fleas Daphnia magna Strauss and Daphnia pulex Leydig, but his attempts to cultivate this parasite were unsuccessful. Subsequent reports on bacteria resembling $P$. ramosa fall into two categories. Cultures studied by one group of investigators $(3,4,17,23)$ failed to form all of the life stages reported by Metchnikoff; the observations of these investigators led to a reevaluation of the description of $P$. ramosa $(1,3$, 17) and to the eventual designation of the current type strain of $P$. ramosa sensu Staley, strain ATCC 27377 (17). A second group of investigators, who apparently were unaware of the work of Metchnikoff $(5,6,12,21)$, described and illustrated a few "yeast and fungal" parasites of Daphnia species and designated some of these as belonging to the genus Dermocystidium. To us, these latter organisms appear to be identical to $P$. ramos $a$ as originally described by Metchnikoff.

We isolated $(13,15)$ from the water flea Moina rectirostris Leydig a cladoceran parasite (CP) which appears to be more similar to the description of Metchnikoff than the type strain proposed by Staley (strain ATCC 27377). Although we have been unable to culture this organism, we believe that the unusual morphology, ultrastructure, staining reactions, and distinctive sequence of parasitic life stages of our bacterium are sufficient to reaffirm the original description of $P$. ramos $a$ by Metchnikoff.
Recently, Mankau (7) described the bacterium "Bacillus penetrans" Mankau, which has morphological and ultrastructural similarities to $P$. ramosa. " $B$. penetrans" has been studied in various plant-parasitic nematodes $(7,14,20,22)$. Our specimen (14) of this nematode parasite (NP) resembles CP (13). Our description of NP is based on the biology, morphology, and ultrastructure of the bacterium in the host nematode Meloidogyne incognita Kofoid and White. In this paper we provide information that suggests a generic relationship between CP and NP.

\section{MATERIALS AND METHODS}

Bacterial specimens. Specimens of CP (Fig. 1, 3, and 5) were found in the hemolymph of cladocerans (Moina rectirostris) which were taken from a pond near Beltsville, Md. Preliminary attempts to culture $\mathrm{CP}$ in vitro on different media failed (13). Consequent$1 \mathrm{y}$, we undertook cultivation in vivo.

Infectious spores of NP (Fig. 2, 4, and 6) were found adhering to the cuticles of larvae of Meloidogyne incognita, a sedentary nematode that parasitizes roots of pepper (Capsicum annuun L.). Attempts to culture NP in vitro failed (14); therefore, its life cycle was followed in nematode hosts that were reared on the roots of tomato seedings.

A culture of strain ATCC 27377 was obtained from the American Type Culture Collection, Rockville, Md.

Maintenance and cultivation. Numerous laboratoryreared cladocerans were used as hosts for $\mathrm{CP}$. The methods used to cultivate the cladocerans and the inoculation of CP, as well as the methods used to study the life cycle of NP, have been described previously (13-15) 
Strain ATCC 27377 was grown in vials of Caulobacter liquid medium (2) in which glass cover slips served as inert substrates for bacterial attachment.

Light microscopy. Cladocerans were filtered from an aquarium onto a 200-mesh screen and then backwashed into a $150-\mathrm{mm}$ plastic petri dish containing a counting grid. Excess water was removed with a pipette to leave the cladocerans immobilized in a thin water film on the bottom of the dish. The dish, which was covered to prevent further evaporation of water, was placed on the stage of a Leitz inverted microscope, where the contents of the cladoceran coeloms were examined at $\times 250$ for the presence of parasites. Parasitized individuals were selected for Giemsa staining by the Lillie method or Gram staining by the Hucker modification. We also examined specimens of Dermocystidium dapniae (an organism similar in appearance to $P$. ramosa) which had been stained with Giemsa stain, prepared, and loaned to us by Weiser (21).

The developmental stages of NP were obtained by macerating tomato roots in a 50\% solution of Pectinol (Rohm and Haas, Philadelphia, Pa.). The macerated roots were shaken in water to dislodge the nematode larvae and adults. The freed nematodes were transferred to glass slides and examined. Nematodes with NP were crushed on slides, air dried, and stained with Giemsa or Gram stain.

Cover slips were taken from Caulobacter medium after cells of strain ATCC 27377 had grown and adhered to both surfaces. The bacteria were cleaned from one surface and the other surface, was stained and observed with the light microscope.

Transmission electron microscopy. Cladocerans that contained stages of CP were selected and fixed in $3 \%$ glutaraldehyde for $24 \mathrm{~h}$ and then washed in six changes of $0.05 \mathrm{M}$ potassium phosphate buffer $(\mathrm{pH} 6.8)$ over a period of $1 \mathrm{~h}$. The parasitized cladocerans were postfixed in $2 \%$ osmium tetroxide for $2 \mathrm{~h}$ and dehydrated in a graduated acetone series (beginning with $10 \%$, followed by an increase of $10 \%$ every $20 \mathrm{~min}$ to $100 \%$ ). After dehydration, the specimens were infiltrated with the low-viscosity resin mixture of Spurr (16).

Root galls containing nematodes infected with NP were placed in a solution of $3 \%$ glutaraldehyde in 0.05 $\mathrm{M}$ phosphate buffer. The galls were cut into 2- to 3-mm segments and transferred to glass vials containing the buffered fixative. In addition, mature parasitized females about 30 days old were dislodged from roots with a scalpel, hand-picked with a Pasteur pipette, and crushed in molten $3 \%$ agar at $50^{\circ} \mathrm{C}$. This procedure caused sporangia to disperse in the agar for easier observation. The agar was allowed to solidify and then was placed in $3 \%$ glutaraldehyde for $1.5 \mathrm{~h}$. The agar was then washed in six changes of buffer over a period of $1 \mathrm{~h}$. The galls and agar containing crushed females were postfixed in $2 \%$ osmium tetroxide for $2 \mathrm{~h}$, dehydrated in the acetone series described above, and infiltrated with a low-viscosity medium. The embedded cladocerans containing $\mathrm{CP}$ and the selected root galls containing nematodes parasitized by NP were sectioned on a model MT-2 ultramicrotome (Ivan Sorvall, Inc., Norwalk, Conn.) with a diamond knife. Thin sections were mounted on uncoated copper grids ( 75 by 100 mesh) and stained with $2 \%$ aqueous uranyl acetate for $10 \mathrm{~min}$ and then with lead citrate for $5 \mathrm{~min}$ (11). Thin sections were viewed with a Philips model
200 electron microscope operated at $60 \mathrm{kV}$ with $20-\mu \mathrm{m}$ apertures.

Scanning electron microscopy. Stages of CP were also prepared for scanning electron microscopy by crushing parasitized females on aluminum stubs. The liberated sporangia were allowed to air dry before coating and examination.

Second-stage larvae of the root knot nematode encumbered with NP spores were prepared for scanning electron microscopic examination by chemically fixing the specimens with $3 \%$ glutaraldehyde in $0.05 \mathrm{M}$ phosphate buffer for $1.5 \mathrm{~h}$, dehydrating them in a series of ethanol solutions $(20,40,60,80$, and $100 \%)$, and critical point drying with liquid $\mathrm{CO}_{2}$. The NP and $\mathrm{CP}$ stages were examined with a Hitachi model HHS$2 \mathrm{R}$ scanning electron microscope operated at 15 or 20 $\mathrm{kV}$.

\section{RESULTS}

Morphology and staining reactions. The developmental stages of CP and NP varied in size (Table 1), but the sequential changes beginning with the cauliflower-like microcolonies that formed fan-shaped quartets of sporangia, then doublet sporangia, and finally single sporangia were the same for both forms. The vegetative cells of CP and NP were gram positive. Thinsection electron microscopy showed that the structure of the cells and the mode of division were consistent with the characteristics of other gram-positive organisms (Fig. 7 and 8).

Vegetative growth. The germination and penetration of CP cells into their hosts have not been described. Thin sections of cladocerans showed $\mathrm{CP}$ cells in muscle tissue (Fig. 9) and in the hemocoele on day 4 (Fig. 11). The filaments comprising the colonies were septate. The width of the hyphal strands was $0.67 \pm 0.06 \mu \mathrm{m}$ (average \pm 1 standard deviation), and the strands were bound by a compound wall that was $14.5 \mathrm{~nm}$ thick and was composed of outer and inner membranes. The inner membrane of the wall formed septations and delineated individual cells. In addition, this membrane was continuous with a membrane complex or mesosome that was occasionally associated with a septum (Fig. 7).

Filamentous cells of NP were initally encountered on day 8 beneath the cuticle of a nematode near the site of penetration. From the site cell filaments colonized the hypodermal and muscle tissues (Fig. 10) and finally entered the pseudcoelom (Fig. 12). The cell measurements (Table 1) and cell wall structure were similar to those of CP. The collapse and lysis of intercalary cells in the microcolonies of $\mathrm{CP}$ and NP suggest a possible mechanism for the formation of daughter colonies and result in the numerous separate final sporangia.

Sporulation. The sporulation process in $\mathrm{CP}$ and NP involved the terminal filamentous cells 

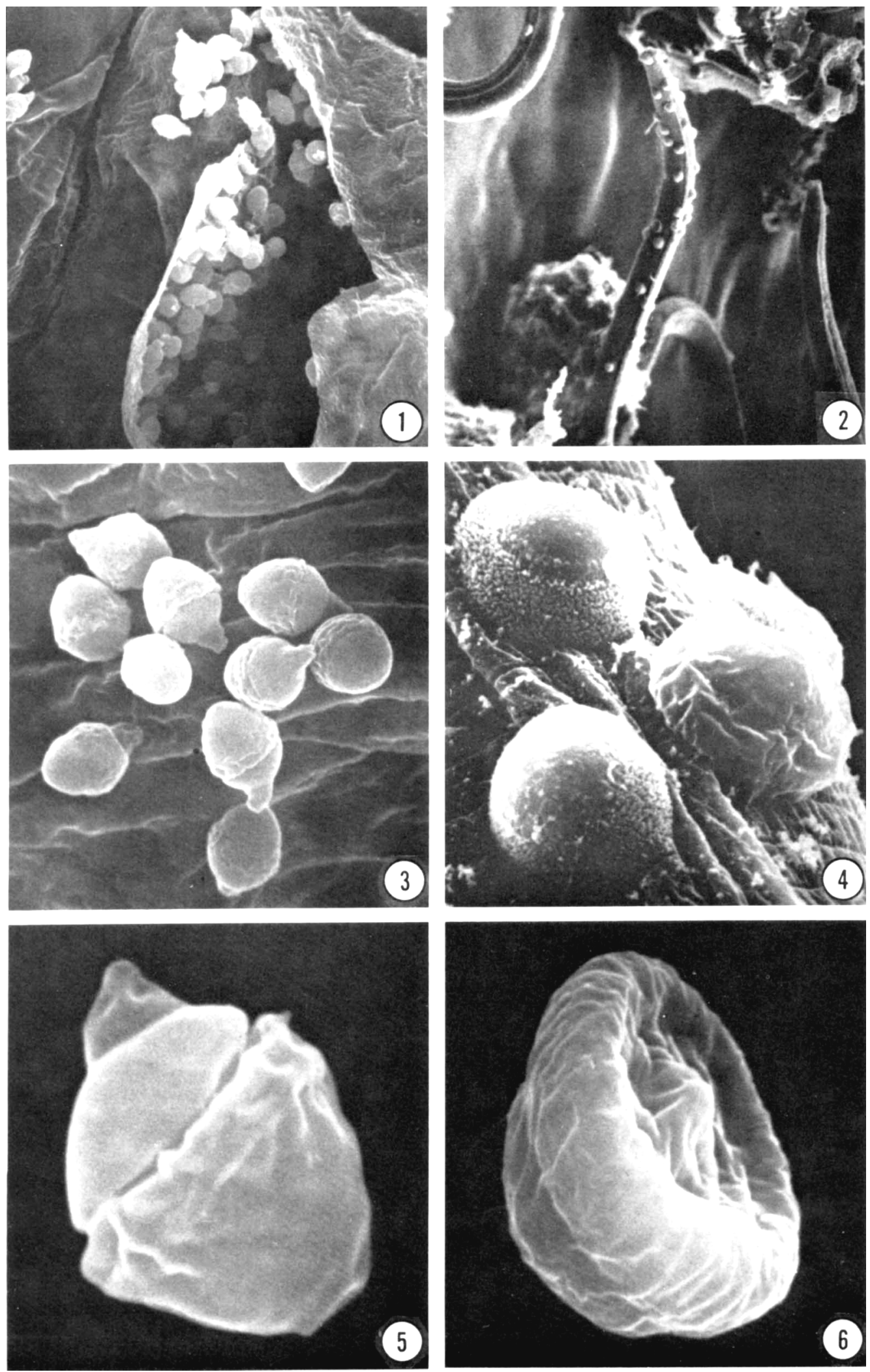
of the microcolonies (Fig. 13). When the process began, the terminal cells enlarged and became ovate. The cytoplasm of the cells changed from cytoplasm that had a granular matrix containing many ribosomes, as found in the vegetative filaments, to cytoplasm that lacked well-defined organelles. During the change, the developing sporangia separated from their parental cells, which ceased growing and eventually degenerated.

After these early alterations, a transverse membrane formed within each sporangium, separating approximately the upper one-third of the cell or forespore from the lower parasporal portion (Fig. 14 and 15). The cytoplasm confined in the upper one-third appeared to condense into an electron-opaque body (Fig. 16 and 17), which eventually was encircled by multilayered walls that collectively formed an endospore (Fig. 18 and 19).

After the formation of the endospore, differences in the development of the parasporal structures of CP and NP became apparent. In $\mathrm{CP}$, light areas that appeared in the median parasporal section expanded and attached laterally to the multilayered spore wall (Fig. 18). In these areas, fibers emerged and formed an inverted "wing" surrounding the wall of the spore (Fig. 20). The degradation of the sporangial wall was not studied; consequently, the appearance of free spores of CP was not determined.

In the final development of NP sporangia, fine fibers, which formed around the base of the endospore, could be differentiated from an electron-translucent granular substance (Fig. 19). These fibers were connected with and radiated from the external layer of the wall of the endospore. During the development of the parasporal fibers, the formation of another membrane, the exosporium, isolated the newly formed endospore within the sporangium. At this late stage of development, the contents of the paraspore degenerated. As a result, the sporangial wall collapsed about the endospore; this process accounts for the large difference between the lengths of the mature sporangia of $\mathrm{CP}$ and NP (Table 1).

\section{DISCUSSION}

$P$. ramosa was described by Metchnikoff (8) as being parasitic on the cladocerans Daphnia magna and Daphnia pulex. Metchnikoff further described a complex life cycle, culminating in the formation of endospores and the subsequent death of the host Daphnia. Unfortunately, Metchnikoff was unable to cultivate this organism, which apparently was lost. Subsequent studies by Staley (17) on a freshwater isolate from Lake Lansing, Mich., led to the designation of a type strain for $P$. ramosa (strain ATCC 27377). Staley failed to note whether this strain was parasitic on Daphnia; in addition, strain ATCC 27377 does not form endospores or the complex morphological stages described by Metchnikoff.

The similarities between $P$. ramosa and $\mathrm{CP}$ begin with the rare occurrence of both organisms in nature. Metchnikoff (8) reported finding the bacterium only twice, and he considered it rare because it occurred less frequently than the other parasites that he found in water fleas. In both instances the organism occurred only during the summer months in ponds crowded with the cladoceran hosts. Similarily, during our 3 years of observation, several kinds of cladoceran parasites were observed; however, we did not find CP until after mid-July of each year. In August, CP reached its maximum incidence, when Moina rectirostris was the most abundant cladoceran species present in the pond. In later laboratory tests (13), the parasite developed only at water temperatures above $26^{\circ} \mathrm{C}$, which seems to confirm the need for summer temperatures.

Metchnikoff first found P. ramosa in Daphnia pulex and then 3 years later found it in Daphnia magna. CP was found in Moina rectirostris but not in Daphnia ambigua Scourfield, which was also present in the pond; Daphnia magna and Daphnia pulex were not present in the pond. When Daphnia pulex and Daphnia magna were obtained from other sources and challenged with spores of $\mathrm{CP}$, the parasite did not develop in either species. There is dissimilarity in host preference between $P$. ramosa and CP. Howev-

FIG. 1 through 6. Scanning electron micrographs of sporangia of CP and NP.

FIG. 1. Sporangia of $C P$ within the ruptured cuticle of a water flea (Moina rectirostris). $\times 2,600$.

FIG. 2. Larvae of the root knot nematode Meloidogyne incognita encumbered with spores of NP. $\times 440$.

FIG. 3. Several sporangia of CP on the cuticular surface of a water lea. $\times 6,600$.

FIG. 4. Three spores of NP adhering to the cuticular surface of a nematode larva. The spores are attached along the slightly raised lateral field of the larva. $\times 12,000$.

FIG. 5. Mature sporangium of CP, showing a stem section, a midvesicle, and an anterior cap. $\times 24,000$.

FIG. 6. Mature sporangium of NP, showing the attaching surface. The sporangium is covered with a thin membranous exosporium. When the exosporium is lost and the attaching surface of the spore is exposed, firm contact with a nematode is followed by germination, which reinitiates the bacterial cycle. $\times 20,000$. 


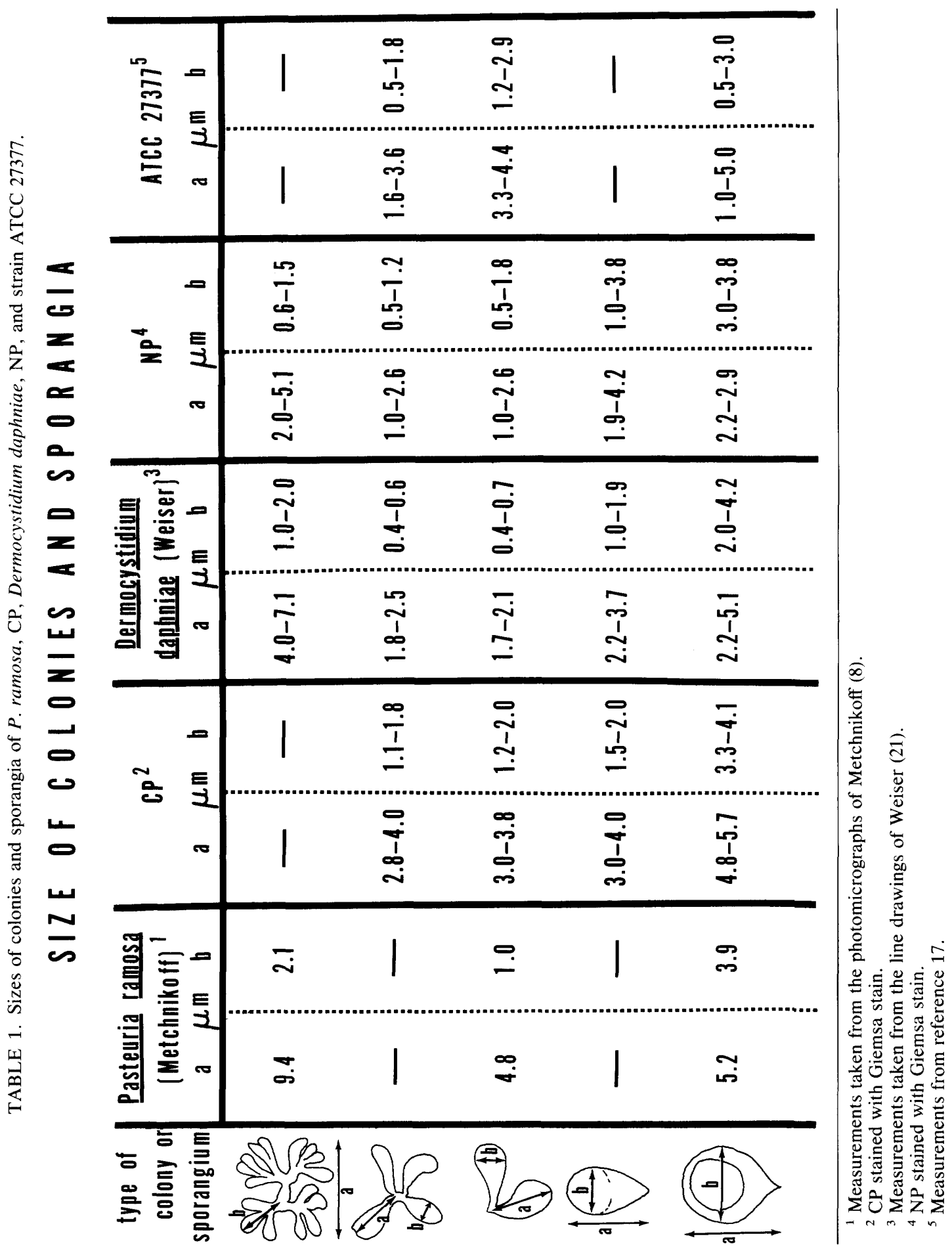



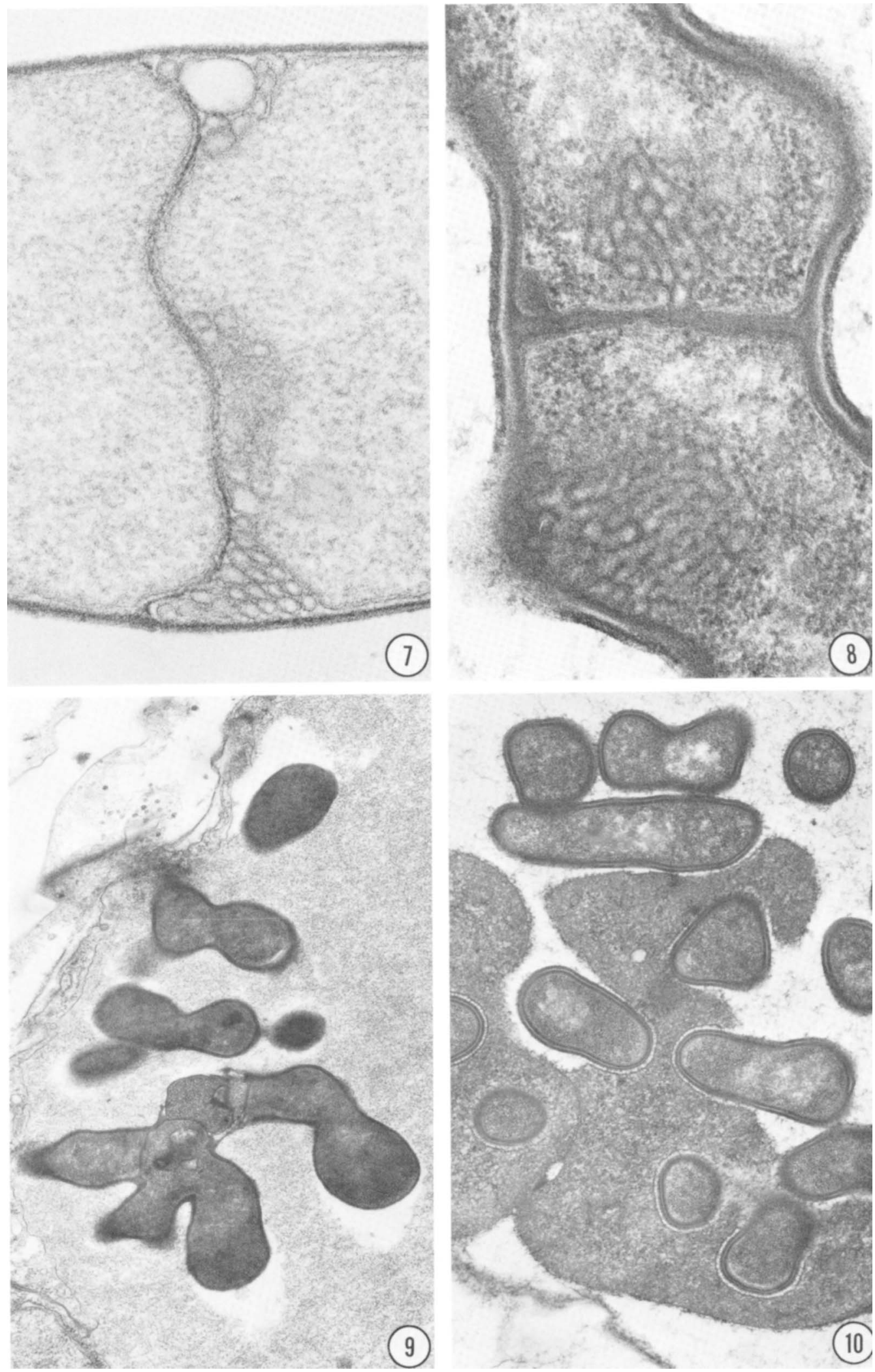

FIG. 7. Section through a vegetative cell of $\mathrm{CP}$ within its host, showing the mesosomes that are occasionally found in association with a septum. $\times 78,000$.

FIG. 8. Section through a vegetative cell of NP within its host, showing the mesosomes that are occasionally found in association with a septum. $\times 88,000$.

FIG. 9. Portion of a CP colony embedded in a granular matrix in the hemocoel of Moina rectirostris. $\times 16,000$.

FIG. 10. Filaments of NP surrounded by a granular matrix in the pseudocoelom of a nematode. Short projections, which are evident on the filament surfaces, result in the clear surrounding "halos." $\times 26,000$. 

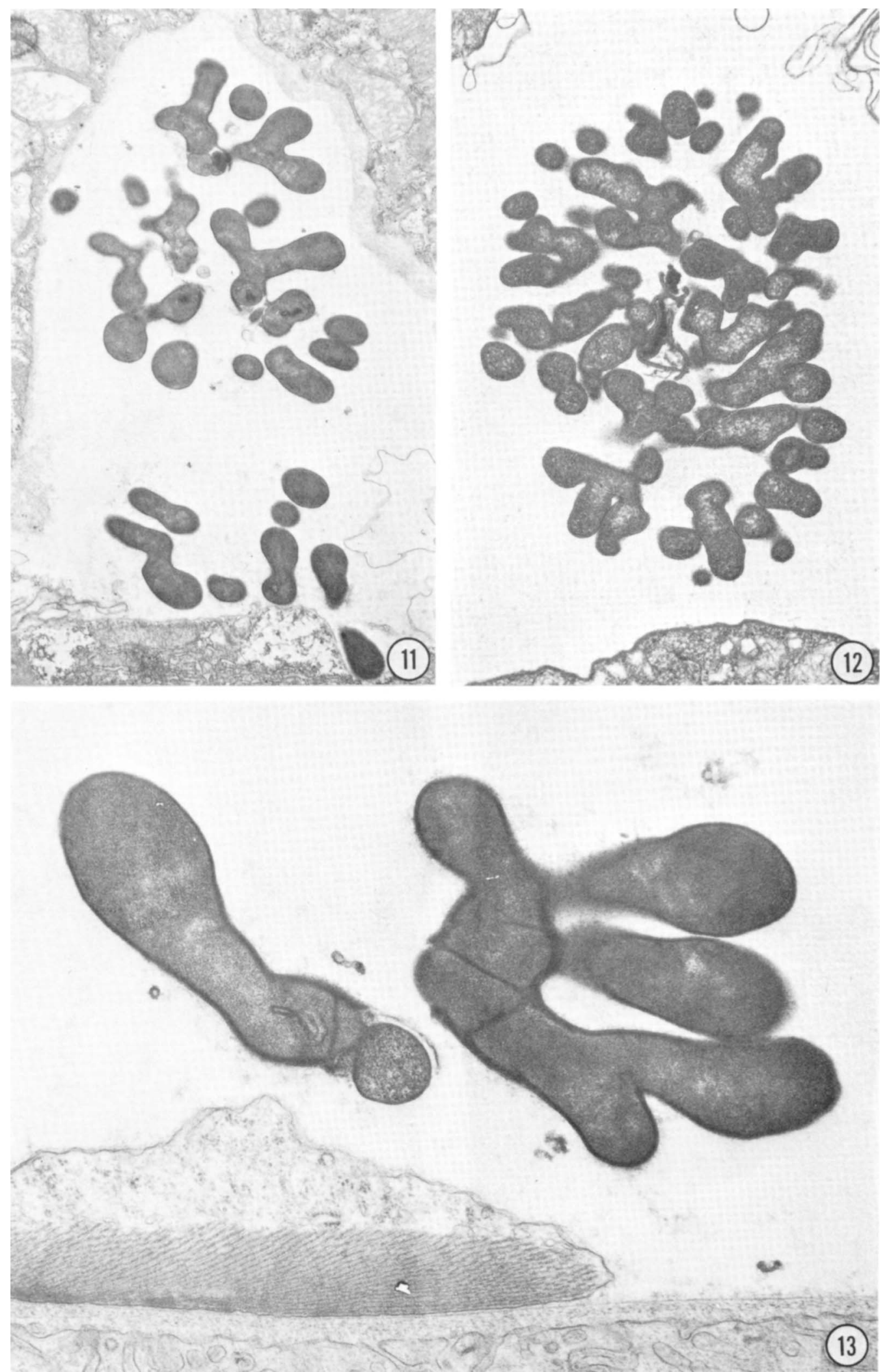

FIG. 11. Colonies of vegetative cells of CP found in the hemocoel of Moina rectirostris, $\times 8,000$.

FIG. 12. Colonies of vegetative cells of NP located in the pseudocoelom of Meloidogyne incognita. $\times 9,000$.

FIG. 13. Portion of a colony of $C P$ that has begun to sporulate. The terminal cells have enlarged into ovate structures that will separate from the parental filaments and become sporangia. $\times 26,000$. 


$$
10
$$




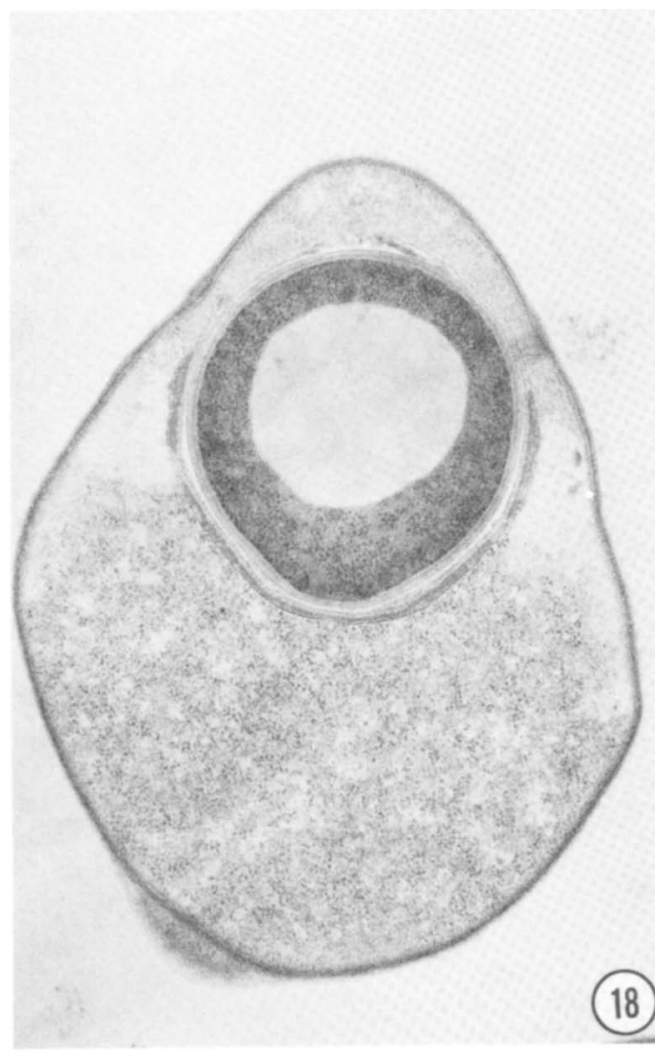

18

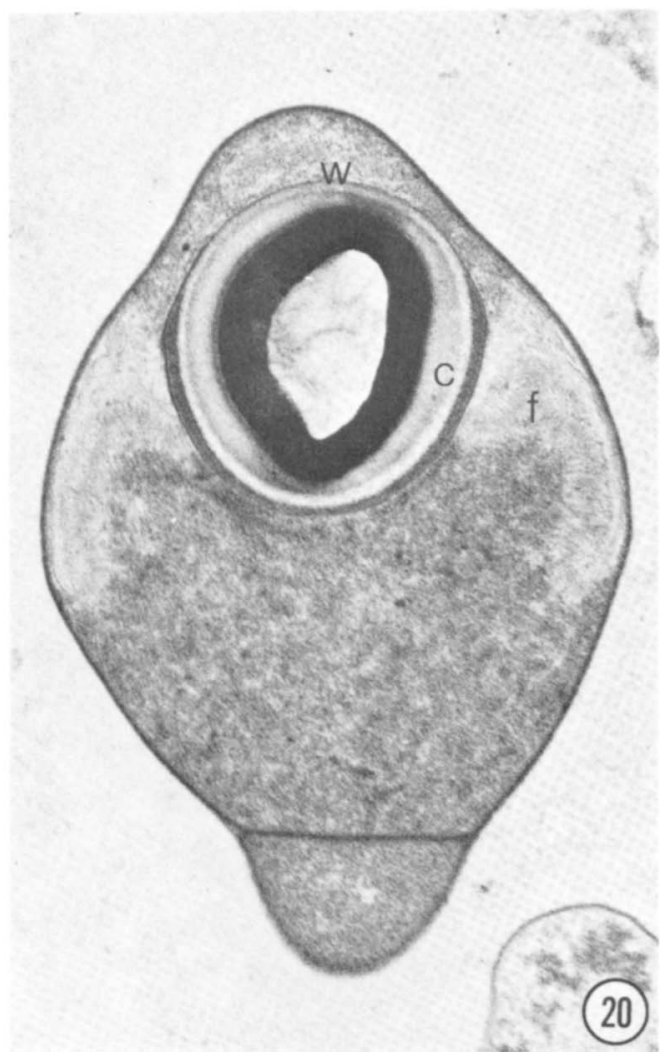

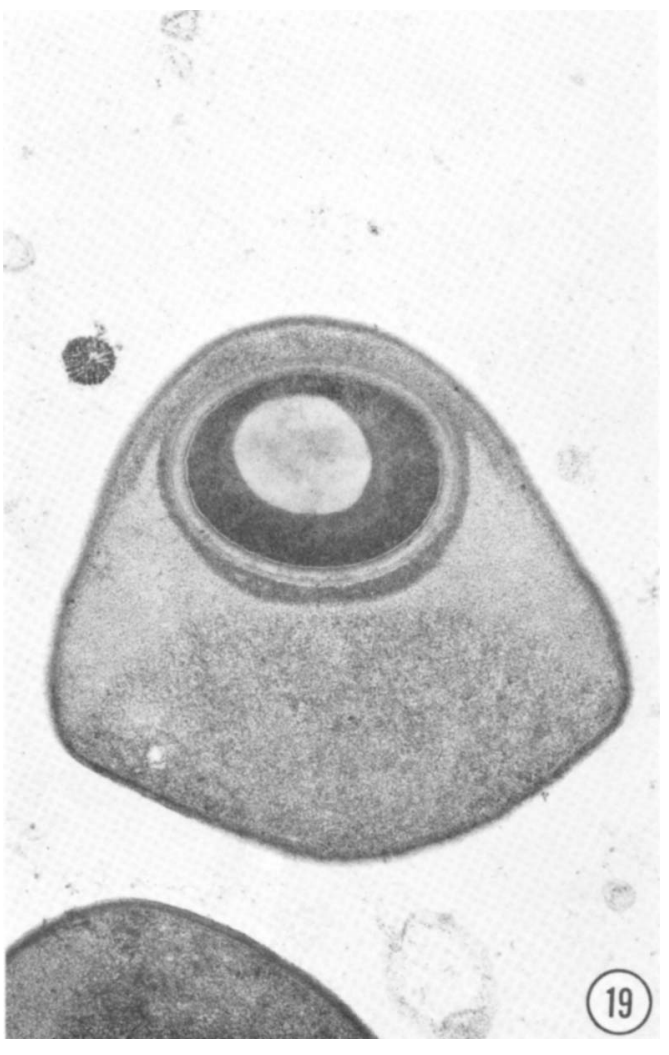

FIG. 18. Sporangium of CP containing a partially formed endospore. At this stage, the walls are not completely developed; only one or two membranes surround the spore. $\times 26,000$.

FIG. 19. Sporangium of NP containing a partially formed endospore. At this stage the walls are not completely developed; several electron-dense layers partially surround the spore. The lateral regions, which differentiate into the parasporal fibers, are more pronounced in NP than in CP. $\times 24,000$.

FIG. 20. Section through a fully developed endospore of CP. The spore has a cortex (c) and multilayer wall (w) typical of endogenous sporeformers; an atypical parasporal structure encircles and attaches laterally to the spore wall. Fibers (f) occur on the undersurface of the lateral structure. $\times 22,000$. 
a
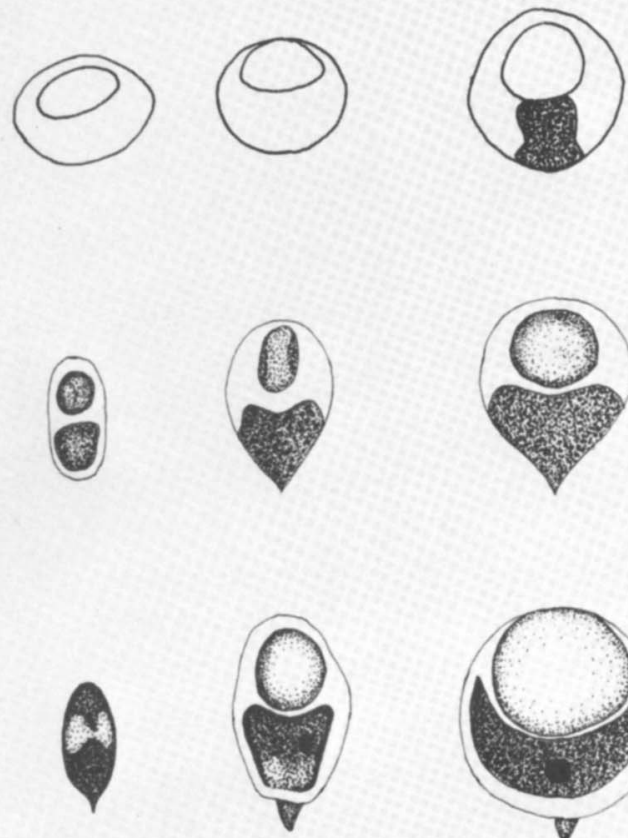

b
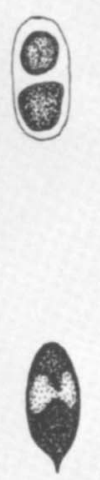
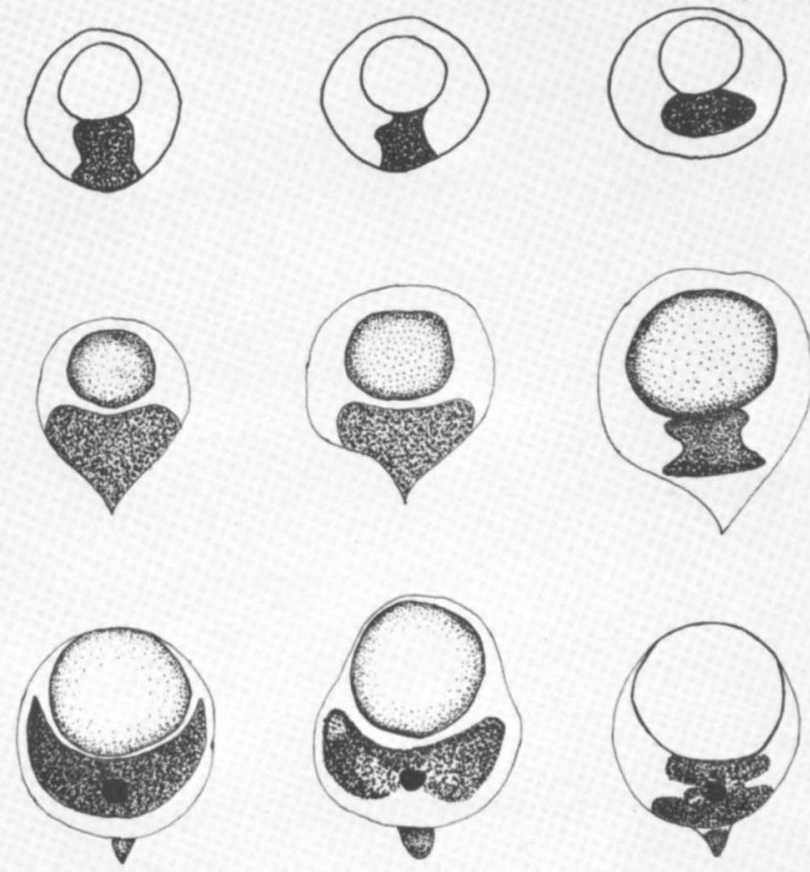

(21)

FIG. 21. Drawings adapted from the studies of Ruhberg (12) (a), Jirovec (5) (b), and Weiser (21) (c), illustrating similarities in the observations of these workers on parasites taken from Dapnia sp. Using a Giemsa procedure, these investigators observed spherical inclusion bodies that stained only weakly, whereas the hourglass-shaped inclusions with a "nucleus" stained intensely.

er, CP does parasitize one species from the family Daphnidae, Moina rectirostris. A comparison of both the sequences and the morphologies of the life stages of $P$. ramosa and CP revealed no differences. However, when measurements of the life stages of $P$. ramosa taken from the illustrations of Metchnikoff are compared with measurements for $\mathrm{CP}$, the measurements for $\mathrm{CP}$ are consistently smaller, suggesting the possibility of a varietal or strain difference between the two organisms. This difference may only reflect the methods used to prepare the two organisms of staining. Metchnikoff did not give detailed reactions of the bacterium for all of stains that he used, but he did report that the rapidly enlarging spherical inclusion in the anterior portion of the sporangium became progressively more difficult to stain and more refractive. He concluded that the spherical inclusion was an endospore, which was typical of other sporeforming bacteria.

Our electron microscopic studies of CP revealed the typical sequence found in endoge- nous spore formation; a septum was laid down within the developing sporangium, a forespore formed within the cytoplasm that had been walled off, a multilayered wall and cortex formed around the spore, and finally at maturity the spore possessed resistance to desiccation and survived in storage. Consequently, we concluded that $\mathrm{CP}$ is an endogenous sporeformer similar to $P$. ramosa. Strain ATCC 27377 was not observed to form endspores and thus differs from $P$. ramosa Metchnikoff 1888 in this respect.

Other isolates similar to $P$. ramosa. Ruhberg (12), Jirovec $(5,6)$, and Weiser (21) described cladoceran parasites that were similar in appearance to $\boldsymbol{P}$. ramosa. Each of these authors stained and presented drawings of his microorganism (Fig. 21) and offered suggestions as to its identity. Ruhberg (12) considered the organism a yeast, perhaps a Torula species. His organism stained intensively with Gram stain, but an eccentric light-refractile vacuole in the cell remained colorless (Fig. 21a). Similarly, Jirovec 


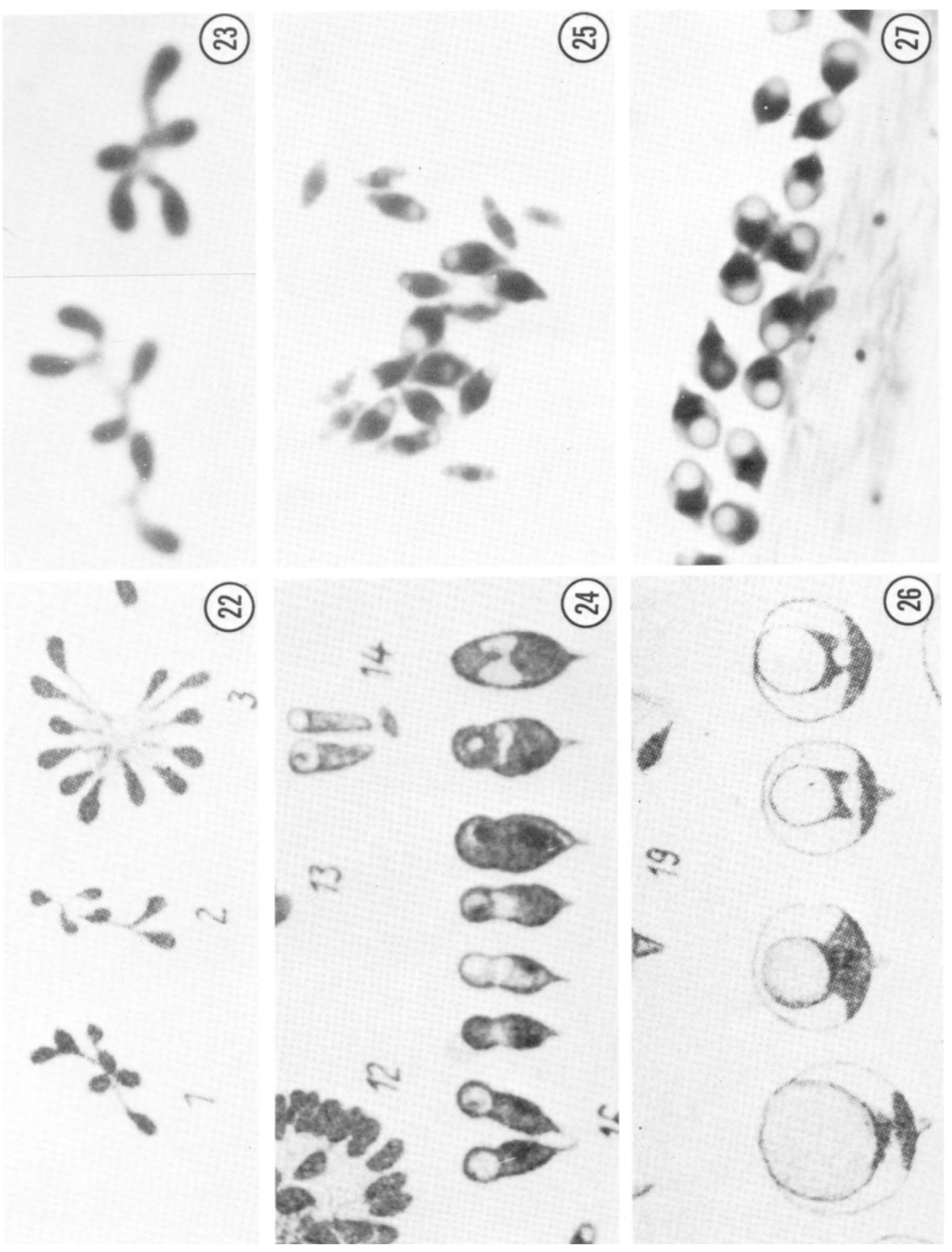


FIG. 22 through 27. Photocopies of original drawings by Weiser (21) of Dermocystidium daphniae (Fig. 22, 24 , and 26) compared with photomicrographs of CP stained by the Giemsa procedure (Fig. 23, 25, and 27).

FIG. 22. Photocopies of drawings of Dermocystidium daphniae showing the stained vegetative microcolonies.

FIG. 23. Photomicrograph of immature vegetative colonies of $\mathrm{CP}$ found in the hemolymph of Moina rectirostris. $\times 4,200$.

FIG. 24. Drawing of Weiser showing several immature sporangia of Dermocystidium daphniae.

FIG. 25. Photomicrograph of stained immature sporangia of CP. $\times 2,200$.

FIG. 26. Drawings of mature sporangia of Dermocystidium daphniae showing "colorless" spherical "inclusion bodies" over a darkly stained "nucleated" structure.

FIG. 27. Mature sporangia of CP with colorless endospores and stained parasporal structures. $\times 2,200$.

(5), apparently aware only of the efforts of Ruhberg, found a cladoceran parasite in Daphnia magna and Simocephalus vetulus. Sporangia of his organism were spherical and 4 to $5 \mu \mathrm{m}$ in diameter and enclosed a strongly light-refractile inclusion body (Fig. 21b). The inclusion body (diameter, 1.5 to $2.6 \mu \mathrm{m}$ ) was eccentric in the cell, remained colorless after staining, and sometimes displayed concentric layering. Jirovec recognized his organism as a possible Torula sp.; later (6) he reconsidered the designation and placed this organism in the fungal genus Dermocystidium. Weiser (21), a student of Jirovec, reexamined parasitized Daphnia magna and the materials of Jirovec (Fig. 21c) and proposed that a new generic name, Lymphocystidium, be applied to the parasite found in the lymph of Daphnia magna (Fig. 22, 24, and 26). Although there are differences in measurements between the two life stages of Dermocystidium daphniae and CP (Fig. 23, 25, and 27), the life stage sequences and general morphologies are the same (Table 1). When CP was stained with Giemsa stain (Fig. 23 and 25), the developing sporangia appeared to be identical to those described by Weiser (21). Pictures of a parasporal body shaped like an hourglass, were published by Ruhberg (12), Jirovec (5), and Weiser (21); such a body was also found in CP (Fig. 27).

Electron micrographs of CP (Fig. 29) reveal
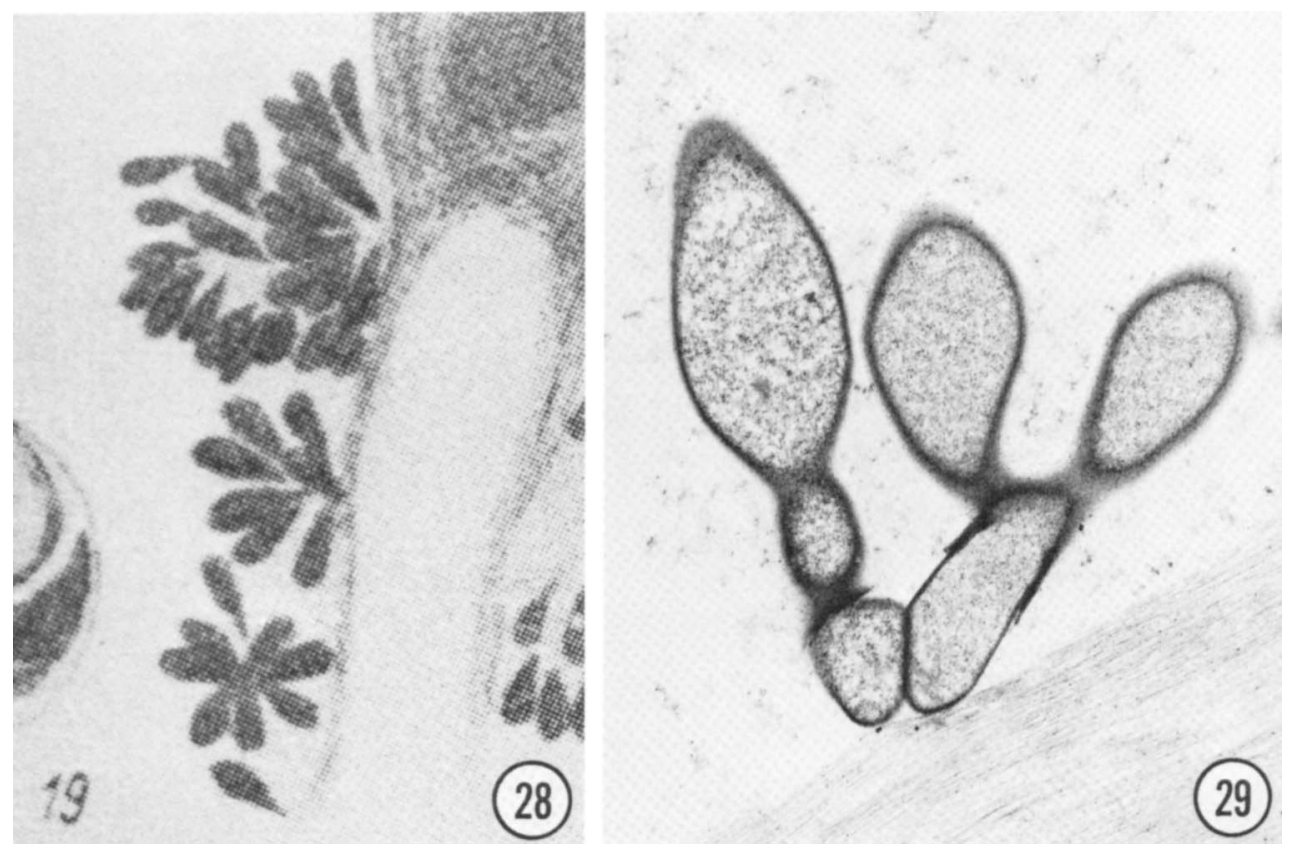

FIG. 28 and 29. Comparison of the similarity in the attachments of Dermocystidium daphniae and CP to tissues of their hosts.

FIG. 28. Drawing of Dermocystidium daphniae showing numerous colonies attached to tissues lining the hemocoelom of Daphnia magna.

FIG. 29. Electron micrograph of a section of $\mathrm{CP}$ showing the attachment of a microcolony to a fibrous substrate found lining the walls of the hemocoelom of Moina rectirostris. $\times 19,200$. 
sporangia attached to cladoceran tissue. This was typical of the attachment found and illustrated by Weiser (21) (Fig. 28).

Pathogenic significance. The nematode and water flea hosts differ widely in their taxonomic positions in the animal kingdom. However, these animals provide similar ecological niches for the development of NP and CP from the earliest vegetative stage to final release of the spores into the environment. The young vegetative microcolonies of CP and NP are found in hemolymph, which not only provides the substrate for growth but also allows space for fragmentation to occur and for daughter colonies to form. Both hosts continue to feed, molt, and reach maturity despite the increasing numbers of microcolonies streaming through their body cavities. Sporogenesis occurs late in the cycle in both hosts, perhaps triggered by a dwindling food supply or the accumulation of metabolic products. Both adult hosts are transformed into bags of sporangia that, upon decay, release thousands of sporangia into the environment; $\mathrm{CP}$ sporangia are released into the mud and pond sediments, whereas NP sporangia enter soils.

Daphnia spp. as alternate hosts for Dermocystidium sp. Perez (9) and Reichenbach-Klinke (10) suggested that some cladocerans are possible vectors or alternate hosts of Dermocystidium species. Sterba and Naumann (18) tested this hypothesis by adding spores of Dermocystidium granulosum to a culture of Daphnia sp.; $36 \mathrm{~h}$ later adult water fleas were found to be parasitized. The organism found by these authors, which occurs in the hemocoels of water fleas, appears to us to be identical to CP and $P$. ramosa (18). When parasitized Daphnia individuals were later fed to the fish species Xiphophorus helleri, no Dermocystidium lesions occurred on the fish even after 9 months of observation in a laboratory aquarium. In the experiment of Sterba and Naumann Daphnia strains were not demonstrated to be alternate hosts.

Classification. The marked differences between the designated type strain of $P$. ramosa (strain ATCC 27377) and the original organism described by Metchnikoff leaves little doubt that strain ATCC 27377 is not a member of the genus Pasteuria and thus should not be considered the type strain of $P$. ramosa. This view is also shared by Tekniepe et al. (19).

Although CP and NP do conform to the classical description of $P$. ramosa, the fact that these organisms have not been isolated in pure culture deters us from a premature designation of $\mathrm{CP}$ as the neotype strain for $P$. ramosa. Both CP and NP are probably members of the genus Pasteuria.

\section{ACKNOWLEDGMENTS}

We thank Audrey Carrell and C. Pooley for technical assistance and for preparing the figures and Table 1 . Also we thank Jean Adams for preparing, sectioning, and viewing the cladoceran material and J. Weiser for permission to use his original drawing and prepared specimens of Dermocystidium daphniae.

\section{LITERATURE CITED}

1. Buchanan, R. E., and N. E. Gibbons (ed.). 1974. Bergey's manual of determinative bacteriology, 8th ed. The Williams \& Wilkins Co., Baltimore.

2. Hatt, H. D., M. J. Gantt, and J. Piper. 1982. The American Type Culture Collection catalogue of strains I, 15th ed. American Type Culture Collection, Rockville, Md.

3. Hirsch, P. 1972. Reevaluation of Pasteuria ramosa Metchnikoff 1888 , a bacterium pathogenic for Daphnia species. Int. J. Syst. Bacteriol. 22:112-116.

4. Henrici, A. T., and D. E. Johnson. 1935. Studies on freshwater bacteria. II. Stalked bacteria, a new order of schizoniycetes. J. Bacteriol. 20:61-93.

5. Jirovec, O. 1936. Ubereinige in Daphnia magna Parastierende Mikrosporidien. Zool. Anz. 116:136-142.

6. Jirovec, O. 1939. Dermocystidium vejdovskyi n. sp., ein neuer Parasit des Hechtes, nebst einer Bemerkung uber Dermocystidium daphniae. Arch. Protistenkd. 92:137146.

7. Mankau, R. 1975. Bacillus penetrans n. comb. causing a virulent disease of plant-parasitic nematodes. J. Invertebr. Pathol. 26:333-339.

8. Metchnikoff, M. E. 1888 . Pasteuria ramosa, un representant des bacteries a division longitudinale. Ann. Inst. Pasteur Paris 2:165-170.

9. Perez, C. 1913. Dermocystis pusula, organisme nouveau parasite de la peau des tritons. C. R. Seances Soc. Biol. Paris 63:445-447.

10. Reichenbach-Klinke, H. 1950. Der Entwicklungskreis der Dermocystidien sowie Beschreibung einer neuen Haplosporidienart Dermocystidium percae n. sp. Verh. Dtsch. Zool. Ges, Mainz 1949. Zool. Anz. Suppl. 14:126-132.

11. Reynolds, E. S. 1963 . The use of lead citrate at high $\mathrm{pH}$ as an electron-opaque stain in electron microscopy. J. Cell Biol. 17:208-212.

12. Ruhberg, W. 1933 . Uber eine Hefeinfektion bei Daphnia magna. Arch. Protistenkd. 80:71-100.

13. Sayre, R. M., J. R. Adams, and W. P. Wergin. 1979 Bacterial parasite of a cladoceran: morphology, development in vivo, and taxonomic relationship with Pasteuria ramosa Metchnikoff 1888 . Int. J. Syst. Bacteriol. 29:252262.

14. Sayre, R. M., and W. P. Wergin. 1977. Bacterial parasite of a plant nematode: morphology and ultrastructure. $J$. Bacteriol. 129:1091-1101.

15. Sayre, R. M., W. P. Wergin, and R. E. Davis. 1977. Occurrence in Moina rectirostris (Cladocera: Daphnidae) of a parasite morphologically similar to Pasteuria ramosa (Metchnikoff, 1888). Can. J. Microbiol. 23:1573-1579.

16. Spurr, A. 1969. A low-viscosity epoxy resin embedding medium for electron microscopy. J. Ultrastruct. Res. 26:31-43.

17. Staley, J. T. 1973. Budding bacteria of the PasteuriaBlastobacter group. Can. J. Microbiol. 19:609-614.

18. Sterba, G., and W. Naumann. 1970. Untersuchungen über Dermocystidium granulosum $\mathrm{n}$. $\mathrm{sp}$. bei Tetraodon palembangensis (Bleeker 1852). Arch. Protistenkd. 112:106118 .

19. Tekniepe, B. L., J. M. Schmidt, and M. P. Starr. 1981. Life cycle of a budding and appendaged bacterium belonging to morphotype IV of the Blastocaulis-Planctomyces group. Curr. Microbiol. 5:1-6.

20. Thorne, G. 1940. Duboscqia penetrans n. sp. (Sporozoa, Microsporidia, Nosematidae), a parasite of the nematode 
Pratylenchus pratensis (de Man) Filipjev. Proc. Helminthol. Soc. Wash. 7:51-53.

21. Weiser, J. 1943. Beiträge zur Entwicklungsgeschichte von Dermocystidium daphniae Jirovec. Zool. Anz. 142:200205.
22. Williams, J. R. 1960. Studies on the nematode soil fauna of sugarcane fields in Mauritius. V. Notes upon a parasite of root-knot nematodes. Nematologica 5:37-42.

23. Zavarzin, G. A. 1961 . Budding bacteria. Mikrobiologiya 30:774-791. 